\title{
RETRIEVING L2 WORD STRESS FROM ORTHOGRAPHY: EVIDENCE FROM WORD NAMING AND CROSS-MODAL PRIMING
}

\author{
Amanda Post da Silveira ${ }^{1 \star}$ \\ ${ }^{1}$ Universidade Federal de São Carlos, São Carlos, SP, Brasil
}

\begin{abstract}
This study aims at showing how L1 word stress affects L2 word naming for cognates and non-cognates in two lexical stress languages, Brazilian Portuguese (BP, L1) and American English (AE, L2). Based on the bilingualism literature, there are indications that the access to the lexicon is non-selective, thus, cognate words would have a facilitation effect in recognition in L2 and in L1. Our hypothesis is that co-defining features of words, such as word stress, would be more activated by cognate word pairs in the target language of use. In a first experiment with low frequency cognate words of English and Portuguese (Post da Silveira, et. al. 2014), we noticed that the low frequency caused word stress dominance in bilinguals to emerge in production. We hypothesize that words of higher frequency in the lexicons will provide more lexical effects of word stress than low frequency words. In order to test this hypothesis, in Experiment 1 of this study, Brazilian Portuguese (BP)-American English (AE) bilinguals named a mixed list of disyllabic moderate frequency words in L1 (Portuguese) and L2 (English). In Experiment 2, BP-AE bilinguals named English (L2) disyllabic target words presented simultaneously with auditory Portuguese (L1) disyllabic primes. Voice-onset-times, which will be called Reaction Times along the task, were measured. Our results led to the conclusion that word stress is actually a co-defining lexical feature, because it is directly affected by lexical frequency. We also noticed that word stress has a task-dependent role to play in bilingual word naming. Given the findings of this study, we advocate that word stress must be incorporated in bilingual models of lexical production, lexical perception and reading aloud.

Keywords: Psycholinguistics; Phonetics; Bilingualism; Lexical Representation; Word Stress
\end{abstract}

\footnotetext{
"Professora Visitante de Língua Inglesa do Instituto de Línguas da Universidade Federal de São Carlos. É PhD em Psicolinguística Experimental e Fonética do Bilinguismo pelo Instituto Donders para o Cérebro, Cognição e Comportamento da Universidade Radboud de Nijmegen nos Países Baixos. Fez parte do doutorado no Laboratório de Fonética do Centro para Linguística da Universidade de Leiden nos Países Baixos. É Mestre em Estudos Linguísticos e Licenciada em Letras - Habilitação Língua Inglesa e Literaturas pela Universidade Federal de Santa Maria. E-mail: psyphon.ap@gmail.com. ORCID: https://orcid.org/0000-0002-9451-7005.
} 


\section{Introduction}

In Brazilian Portuguese, the word 'sinal' has a similar pronunciation to the American English word 'signal', and it also has similar meaning. In fact, the words are cognates, translation equivalents that have considerable form overlap. In this case, the orthographic representations of the two words are nearly identical, and the words' pronunciations are similar, differing only in subtle phonemic and subphonemic aspects. However, there is one other difference between the words that should not be overlooked: The position of their word stress. In Brazilian Portuguese, the word stress for 'sinal' is on the final syllable, while in English 'signal' it is on the prefinal syllable. Two intriguing questions arise from this observation. First, how is word stress assigned when bilinguals are reading and naming words in their first (L1) and second language (L2)? Second, what are the consequences of word stress congruence or incongruence across the two languages for the on-line processing of cognates and non-cognates? To address these questions, we first performed a corpus analysis on word stress in the Brazilian Portuguese and English lexicons. Next, we conducted two on-line experiments in which bilinguals speaking Brazilian Portuguese (L1) and English (L2) named words in L1 and L2 that were cognates or non-cognates.

So far, available bilingual word recognition models have not specified the role of word stress in L1 and L2 processing. In a model like the Bilingual Interactive Activation + $(\mathrm{BIA}+)$ model for reading (Dijkstra \& Van Heuven, 2002), orthographic input representations may activate phonological and semantic information stored in the bilingual lexicon, but word stress is not considered as a factor. According to BIA+, in early stages of word recognition, lexical representations that are similar to the presented target item in word form (so-called 'competitors') are coactivated with the target word, irrespective of the language to which they belong. For instance, when a Portuguese-English bilingual reads the Portuguese word 'sinal', not only similar word candidates from Portuguese (like 'sino') are activated, but also candidates from English (like 'signal'). Word retrieval may be slowed down if the letter string has many neighbours in L1 and/or L2 (Van Heuven et al., 1998), because the presented lexical item must compete for recognition with both within- and betweenlanguage competitors. Furthermore, via input orthography, lexical phonological word candidates from the two languages can become active. Thus, in addition to language non-selective activation of lexical orthographic competitors, there is also non-selective activation of their phonological counterparts (Dijkstra, Grainger, \& Van Heuven, 1999). In the case of cognates, these orthographic and phonological form codes activate more or less the same shared semantic representation. Word retrieval is further complicated because of the interactive nature of the word recognition system: It incorporates phonological-toorthographic feedback and semantic-to-orthographic feedback (Seidenberg \& McClelland, 1989). The resulting resonance between representations at different levels explains the ubiquitous finding of a cognate facilitation effect (Dijkstra et 
al., 2010). Cognate pairs like film-film in Dutch and English are recognized faster than non-cognate translation equivalents, because there is both co-activation of the L1 and L2 word form representations and resonance with shared semantics. Such resonance is absent for interlingual homographs such as room-room in Dutch and English - which have identical orthography but different phonology and meaning - thus resulting in no facilitation effects or even inhibition effects for these items (see Dijkstra, 2007, for an overview). Finally, the activation of lexical representations itself depends on the activation of sublexical orthographic and phonological features (Perry et al. 2010).

Indeed, although cognates may be fully identical in their orthographic form across languages, this is rarely the case for their phonological forms, because printto-sound inventories vary considerably across languages (Dijkstra et al. 1999). The consequence of visual and auditory sublexical and lexical overlap for word retrieval within and between languages has been an important topic of research (e.g., Brysbaert \& van Wijnendaele, 2003; Dijkstra et al., 1999; Jared, 2002; Smits et al., 2006, 2009). However, so far this consideration of cross-linguistic (mis) matching overlap has been restricted to the segmental level; little attention has been given to how (in)congruence in L1 and L2 word stress affects lexical competition and target word retrieval. This is remarkable, because word stress seems to be a ubiquitous and inherent property of word retrieval. This is particularly evident in production. In both L1 and L2 word naming, the orthographic input of a written word is converted into a phonological output with a particular word stress. According to Dual Route models (Coltheart \& Rastle, 1994; Coltheart et al., 2001) and the BIA+ model (Dijkstra \& Van Heuven, 2002), this conversion can take place along two routes: from lexical orthographic representations to lexical phonological representations (the direct route), or from sublexical orthographic representations to sublexical phonological representations (the indirect route); however, the assignment of word stress is not clearly considered. The CDP++ model (Perry et al., 2010) holds that both orthographic lexical representations and phonological sublexical representations are activated during L1 word naming on the basis of orthographic sublexical representations (e.g., letters or syllable units). According to the model, a sublexical frame for word stress is activated in parallel to letter-to-sound decoding. The model further proposes a word stress integration frame, separate from segmental and phonotactic information. Although it does not specify how word stress is integrated in speech production, it suggests that stress is only integrated after segmental information has been encoded for articulation. However, this proposal for an independence of word stress and segmental information, typical in speech production models (e.g., Roelofs, 1997; Levelt, Roelofs, \& Meyer 1999) cannot be correct, because word stress can be directly correlated with the segmental sublexical information present in lexical items. For instance, the presence of the reduced-most vowel of English, schwa, is already an indication that the syllable must be unstressed. In other words, when a letter corresponds to a schwa, this has a direct consequence in terms of word stress assignment. In line with this observation, we propose that congruence or 
incongruence of word stress in L1 and L2 word pairs can directly affect bilingual word retrieval, just like overlapping or non-overlapping segmental information across the languages does. This in particular should have consequences for recognizing or naming translation equivalents with form overlap, i.e., cognates. Besides, we manipulated the word frequency to moderate and expect that bilingual speakers will use the lexical route more than to low frequency words as a strategy to retrieve word stress information as part of the knowledge they have of the lexical items. The following parts of this paper are distributed so that there is a literature review section followed by a method section, in which the common parts of the methods used for the two experiments of this study are presented. Subsequently, experiments 1 and 2 are presented separately: each with their own method, results and discussion sections. Finally, there is a general discussion section, and a conclusion section of the paper.

\section{Literature review}

\section{Word stress in L1 printed word naming}

The orthographic depth hypothesis (e.g., Frost et al., 1987; Katz \& Feldman, 1983) posits that readers adopt different strategies depending on the type of their L1 orthographic system. An orthographic system is called shallow (or transparent) if graphemes and phonemes are related in a simple and systematic way (e.g., as in Finnish or Italian) and it is called deep (or opaque) if the mapping between graphemes and phonemes is complex (e.g., as in English). In a shallow orthographic system, L1 readers learn to use sublexical orthography as a reliable means of word reading. In contrast, in a deep orthographic system readers may use a larger portion of the printed word or even whole-word reading to activate phonological word representations (Ziegler \& Goswami, 2005; Perfetti \& Dunlap, 2008). Reading strategies across languages may differ in the predominance of one route or the other, because readers may adapt to the demands of the script type(s) involved (Ziegler et al., 2001).

The (in)consistency of languages with respect to orthographic-phonological mapping can also be accounted for in terms of language-specific word stress representations. Users of lexical stress languages (with unpredictable word stress position) sometimes apply orthographic whole-word strategies to mark the stressed syllable of a word. In Greek, stressed syllables are marked by an orthographic diacritic (Protopapas, 2006a, 2006b). However, most lexical stress languages, including German and Russian, do not make use of diacritics to mark stressed syllables. This makes them relatively deep orthographies with respect to spelling-to-stress correspondences in comparison to the orthographies that do signal word stress graphically. Nevertheless, native and non-native speakers of deep orthographies for word stress assign word stress in reading tasks.

There is evidence that certain sequences of letters are more easily identified as syllables by monolingual readers than others, because the orthotactic sequences 
in question correspond consistently to phonotactic sequences that themselves correspond to word stress information (Jouralev \& Lupker, 2015), for instance, the -mente suffix from Brazilian Portuguese is associated to the prefinal stress pattern and it very likely conveys the word stress position information since the referred sequence of letters is recognized in BP. This implies the existence of a cognitive mechanism that allows readers to derive word stress information from the orthographic representations of words.

L1 word stress decoding based on orthography can happen via the lexical route. Once words are recognized by bottom-up mechanisms, letter nodes activate both the orthographic and the phonological lexicon, so that word stress evidence from the phonological lexicon can be fed to the word stress output nodes (Perry et al., 2010). In addition, language users may apply 'meta-information', e.g., on the regularity and consistency distributions about word stress patterns. For instance, there are indications in L1 word naming studies that words are produced faster when their specific stress pattern has a high frequency in the lexicon at large. Word stress regularities are known to speed up word naming, especially for low frequency words (Colombo, 1992; Rastle \& Coltheart, 2000).

\section{Word stress in L2 printed word naming}

When bilinguals name printed words in their second language, one may expect they name them by applying the grapheme-to-phoneme conversion rules of their L2, not their L1. However, when the script for L2 has a different orthographic depth than that for L1, bilinguals might experience conflicts between the grapheme-tophoneme mappings in the dominant L1 and those in the weaker L2. In that case, they might resort to a reading strategy in L2 that is analogous to or influenced by that in the dominant language. However, this is an untested hypothesis, because only a few studies have considered the recognition and processing strategies L2 readers use (e.g., Jared \& Kroll, 2001; Jared \& Szucs, 2002).

When bilinguals encounter cross-linguistic homographs in L2 word naming and L2 reading, multiple interlingual spelling-to-sound conversions are likely to be made (van Leerdam, 2005). When bilinguals perceive printed L2 words, not only L2 phonology but also L1 phonology plays a role in the decoding process. As an example, van Leerdam gives the orthographic sequence -oo in English that corresponds both to $/ \mathrm{u} /$, as in mood, and to $/ \Lambda /$, as in blood. Here $/ \mathrm{u} /$ is the most consistent correspondence in the English lexicon, while in Dutch, -oo corresponds to the phoneme /o/, as in lood ('lead', the metal). Van Leerdam found that when Dutch-English bilinguals read the word blood in English, three phonemic correspondences (two from L2 and one from L1) associated to the homographic sequence -oo were activated, as well as crosslinguistic lexical enemies, such as lood (Dutch L1) and mood (English L2) (see Figure 1 below). How fast the bilingual system was able to disambiguate the target from enemy candidates correlated with the consistency of the local representations (van Leerdam, 2005). 
Van Leerdam's (2005) conception of L1-L2 merged categories explicitly refers to the mapping of one visual unit in the L2 (a letter or letter string) to two or more phonological categories in L1 and L2. However, the model does not predict L1-L2 merged phonological categories for sounds that are not part of bilinguals' L1 phonemic inventory (see studies on L2 category assimilation or categorization, respectively, by Best, 1995, and Flege, 1995). For the -oo example by van Leerdam (2005), the Dutch sound inventory does not include the English vowel $/ \Lambda /$, so this vowel is merged with a Dutch vowel category close to it in vocalic spectral space, such as /o/. As mentioned above, the letters -oo are pronounced in the Dutch word lood as /lo:t/, and -ood in the English word blood as $/ \mathrm{bl} \Lambda \mathrm{d} /$. The effect of this L1-L2 vocalic merging in reading is increased competition by those Dutch L1 words containing /o/ when the English L2 grapheme-to-phoneme corresponds to $/ \mathrm{N} /$ as in blood and low L1 competition when the spelling corresponds to $/ \mathrm{u} /$ as in mood.

Figure 1 summarizes this argumentation about merged L2 categories in terms of an example. It indicates how an orthographic L2 input word blood feeds forward to phonology (panel a), and how the internal merged phonological category for $/ \mathrm{bl}\{\Lambda, \mathrm{o}:\} \mathrm{d} /$ feeds back to orthography (panel b).

Figure 1. Example of the pattern of words activated in the case of an L1-L2 merged phonological category, during Orthographic to Phonological decoding (panel a) and during Phonological to Orthographic decoding (panel b). The L1L2 Merged Category is included in brackets \{and\}.

(a)

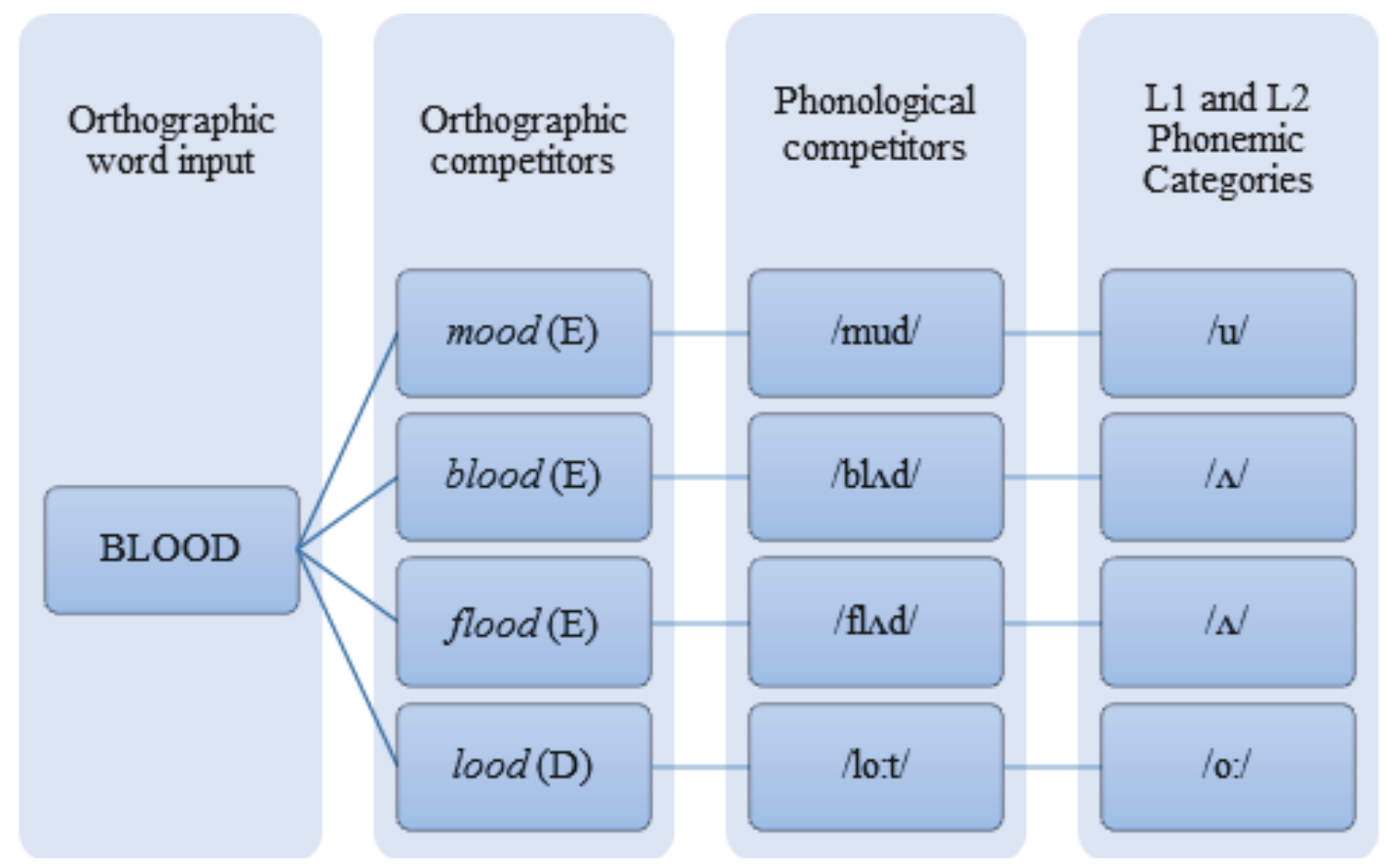


(b)

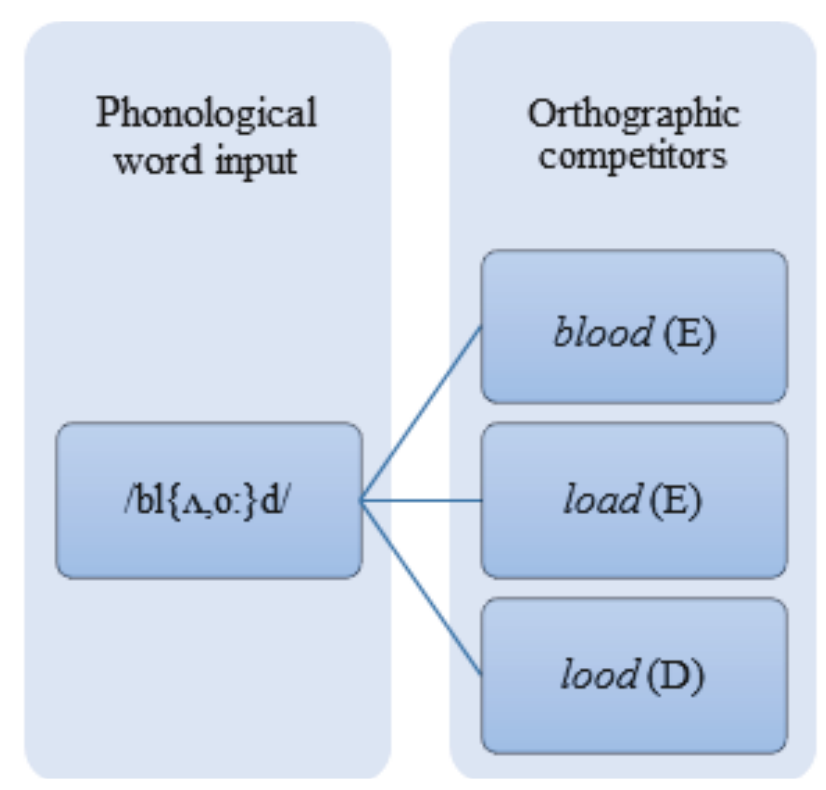

L1-L2 merged letter-to-sound categories are probably not exclusive to bilingual phonemic representations, but may include L2 word stress assignment in L2 reading aloud. We explore the relationship between L2 orthography and L2 word stress in this paper via reading aloud tasks that require readers to recode the orthographic representation of input words into their phonological output forms. Manipulating whether the position of word stress in words is congruent or incongruent across languages may result in cross-linguistic effects if word stress is a sublexical and/or lexical component of word representations in L1 and in L2.

\section{Word stress frequency distributions in Brazilian Portuguese and American English}

In addition to investigating the role of word stress in cognate and non-cognate naming, our study examines the effects of L1/L2 word stress dominance and lexical frequency. Previous studies have observed that word stress representation is affected both by segmental string features (regularities at segmental and phonotactic levels) and stochastic evidence concerning the lexicon (such as word stress frequencies) (Perry et al., 2010). For word stress retrieval in bilinguals, the distributions of stress pattern frequencies and word stress dominance in both the L1 and L2 lexicons might play a role. In some languages, L2 stress assignment is a complex task, especially when word stress can be assigned to different syllable positions within a word, and stress placement is dependent only on word stress frequency distributions from the input, such as it occurs in English (Guion, 2001) and in Portuguese (Cantoni, 2008). In the following, we will characterize the word stress frequency distributions for $\mathrm{BP}$ and $\mathrm{AE}$.

In $\mathrm{BP}$, primary stress is assigned to the ultimate, penultimate, or antepenultimate syllables (Mattoso-Camara Jr., 1953; Bisol, 1992). Among the stress patterns for BP words, penultimate stress is predominant: For 2-4 syllable 
words, it occurs in more than $70 \%$ of all stress positions (Cantoni, 2008; Frota, Vigario, \& Martins, 2010). In contrast, the frequencies of ultimate and penultimate stress are about $20 \%$ and $5 \%$.

From the distributions in AE provided by Clopper (2002), we infer that 2and 3-syllable words are more frequent in English than 4-syllable words or longer, after excluding monosyllabic words. There also is a tendency for the first syllable to be stressed, because the most frequent stress pattern of disyllabic words is penultimate stress (or first syllable stress), while the most frequent stress pattern of trisyllabic words is antepenultimate stress (again, first-syllable stress). The 4-syllable words (or longer) are stressed mostly on the antepenultimate syllable. In 3- and 4- syllable words, penultimate stress is second most frequent. As disyllabic words are substantially more frequent in the English lexicon, penultimate stress is the most frequent stress pattern of English overall.

These stress pattern distributions are mirrored in stress assignment performances (Colombo, 1992; Sulpizio \& Colombo, 2017), as shown by studies investigating the interaction of word frequency and stress regularities in naming latencies of disyllabic words in L1 English (e.g., Monsell et al., 1989; Kelly et al., 1998) and in L1 Italian (Colombo, 1992; Colombo \& Zevin, 2009; Sulpizio, Burani, \& Colombo, 2015). When stress is defined as default on the first syllable of disyllabic words, as suggested by the studies of Chateau and Jared (2003), and Yap and Balota (2009), effects of regularity are found only in low frequency words and errors (Colombo, 1992; Perry et al., 2010).

The present study considered these theoretical issues in two experiments. In the first experiment, BP-AE participants read aloud words from each of their languages in a mixed list. These words included cognates and non-cognates with congruent and incongruent stress in the two languages. In the second experiment, a different group of comparable bilinguals read the same target words, but now primed by auditory items that had different characteristics in common with the targets: The primes consisted of cognates, word translations, or babble noise. We will explain the rationale underlying these manipulations below, after we have discussed the selection of the stimulus materials.

\section{Lexical frequency - lexical route for word stress assignment}

In the word naming task, readers of alphabetic scripts can follow both lexical and sublexical routes to arrive at phonological representations (Coltheart et al., 2001). With respect to the sublexical route, they apply grapheme-to-phoneme conversion rules even when graphemic sequences make no reference to existing words in any lexicon, for instance, in the case of non-words (de Groot et al., 2002). In everyday reading, language users come across unknown vocabulary items (e.g., low frequency words), but that does not prevent them from reading these (aloud) thanks to regularities in grapheme-phoneme correspondences. Thus, the primary process of reading words aloud is an automatic recoding of the graphemic sequence into phonological building blocks for the purpose of articulation and 
vocalization of words, while semantics may be indirectly engaged in the process. Word naming studies have repeatedly shown that word stress assignment plays a role in the involved word form decoding and encoding processes (e.g., Colombo, 1992; Burani \& Arduino, 2004; Colombo \& Zevin, 2009).

In Post da Silveira et al (2014), we investigate the effects of congruent versus incongruent word stress on the naming of low frequency English cognates or non-cognates. Participants are Brazilian-Portuguese (L1) - AE (L2) bilinguals. We examine how L2 word stress is represented and retrieved following the lexical route by manipulating lexical properties of words, such as their Cognate Status, Lexical Frequency, and L1-L2 Word Stress Congruence. If the route of L2 word stress assignment would be mainly lexical for these low frequency words, the cognate status of words and lexical frequency should arise as important factors in word stress accuracy and reaction time performance. Alternatively, word stress dominance (and possibly word stress regularity) might play a more important role for low frequency items. L1-L2 Word Stress Congruence can help in testing word stress dominance in L2 word naming; its effects may be seen in errors and RTs. In referred study, a word stress effect was found in the error rates and naming times of low frequency disyllabic words, but no cognate effect. This latter result can be understood in the light of word naming studies on L1 word stress showing that lexical effects may be absent for low frequency words, while an effect emerges of the dominant word stress pattern in the language as a whole (Colombo, 1992; Colombo \& Zevin, 2009). When the predominant pattern for word stress in AE and BP (pre-final stress) converged, this resulted in an increased L2 error rate. There are two possibilities to account for this result: i) L2 word stress was (re) present(ed) and used in L2 word recognition and production, but affected by the strong L1 system, or ii) L2 word stress assignment was dependent on L1 word stress patterns. We observed that bilinguals used mainly the sublexical route to assign word stress, because they did not have lexical knowledge to support their decision due to the low frequency of the words.

Based on those findings, we hypothesize that words of moderate frequency may change the strategies used by L2 readers concerning word stress retrieval from orthography and the use of the retrieved pattern in word naming. So, in the present study we investigate the roles of cognate status of words (lexical effect), word stress congruency (sublexical processing) in words of moderate frequency of the speakers' L1 and L2.

\section{Method}

\section{Selection of stimulus words for the two experiments}

Because the two experiments consisted of largely shared item sets, we describe the stimulus selection procedure here rather than for each individual experiment. We first generated a list of BP words from the NILC/Sao Carlos (Santos \& Bick, 2000) ASPA corpus (Cristófaro et al., 2005) and a list of English words from 
CELEX (Baayen et al., 1993), selecting words in a frequency range from 10-70 occurrences per million (Cristófaro-Silva, de Almeida, \& Fraga, 2005).

\section{Calculation of L1-L2 lexical distance}

Next, using the English Wiktionary (www.wiktionary.org), we constructed a list of semantically close item pairs by selecting word pairs from our lists that were English-Portuguese translations. We then applied the normalized Levenstein distance (nLd) metric as defined by Schepens et al. (2012) to calculate orthographic and phonological distances between the members of each word pair. We selected our stimuli based on these calculations, which included the typical print-to-sound categorizations that Portuguese speakers make of English patterns (Post da Silveira \& van Leussen, 2015). ${ }^{1}$

Prior to the calculation of phonological distance, the English transcriptions were edited such that English phonemes that do not exist in BP were replaced by their closest categories (Post da Silveira \& van Leussen, 2015). For instance, the short lax high front vowel /I/ was replaced by /i/, because the two vowels do not constitute different categories in the L2 system (Baptista, 2006; Bion et al., 2006; Nobre-Oliveira, 2007). This procedure of pre-categorizing L2 segments according to the L1 phonemic system mimics L2 speakers' grapheme-to-phoneme conversions, their L2 phonological representations, and, consequently, their phonological representation of L2 words. We call the new measure of bilingual segmental representation interlanguage normalized Levenshtein distance (inLd).

\section{Stimulus Categories}

The resulting list of 5,800 English-Portuguese word pairs included the relative frequency of each member of the pair (10-70 opm), their stress pattern in English and Portuguese (congruent or incongruent), number of syllables, number of letters, number of phonemes, and orthographic and phonological distances (words with 0.1 to $0.6 \mathrm{nLd}$ values were defined as non-cognates, words with 0.7 to 1 as cognates).

For each experiment, further stimulus selection then took place. Target items were selected consisting of English-Portuguese form-similar translation equivalents (i.e., cognates), such as signal (English) sinal (Portuguese) and congruent non-cognate words with different forms across languages, such as arrow (English) flecha (Portuguese). The cognates, non-identical word pairs with the same number of syllables, had a minimal - but variable - cross-linguistic distance in terms of orthographic and phonological segmental specification. In addition, they were either congruent or incongruent in word stress. A congruent cognate pair is tiger (English) - tigre (Portuguese), where both English and Portuguese stress fall on the pre-final syllable. An incongruent cognate pair is billion (English) - bilhão (Portuguese), with stress on the pre-final syllable in English and the final syllable in Portuguese. These non-cognates were formunrelated stress congruent or incongruent translations in English and Portuguese with the same number of syllables and letters as the cognates. 
All selected congruent word pairs were matched with respect to semantic relatedness (i.e., they were the closest translation equivalents), Word Frequency, number of syllables, number of letters, stress pattern, orthographic similarity, and phonological similarity. Categories were created by manipulating Cognate Status (English and Portuguese cognate or non-cognate pairs, as defined by inLd values) and Stress Congruence (congruent or incongruent stress position between L1 and L2). Finally, as filler items we selected a large number of trisyllabic words varying on these dimensions.

Word length ( 2 or 3 syllables) was not itself included as a factor, because (1) due to selection restrictions, it was not possible to obtain the minimum of 15 words in each condition for trisyllabic cross-linguistic word-pairs; (2) not enough is known about how lexical activation of cohort members depends on word length in syllables (Marslen-Wilson \& Welsh, 1978); (3) for words of three syllables, the first syllable will be affected by the properties of the subsequent two syllables (Roelofs, 1997). Therefore, trisyllabic words were included in the study as filler items only.

\section{Subjective ratings for L1-L2 lexical distance values}

We next asked five Portuguese native speakers teaching English as an L2 in Brazil to rate our selection of English words with respect to orthographic and phonological similarity to the closest BP translations, as well as familiarity. According to Table 1, the mean ratings on the judges' perception of orthographic similarities between the English-Portuguese translation pairs were very close to the computed inLds. Phonological distances also corresponded quite closely to the L2 speakers' representation of the words they judged from print. Based on the subjective familiarity ratings, we excluded words that fell in a low familiarity range (below 4 on a scale of 1-7). In the end, a total of 100 test stimuli were selected: 60 disyllabic targets and 40 trisyllabic fillers.

Table 1. Correlations between subjective ratings on orthographic similarity, phonological similarity, and familiarity with the computed inLd values.

\begin{tabular}{ll}
\hline & $r$ \\
\hline Orthographic similarity & .95 \\
Phonological similarity & .75 \\
Familiarity & .26 \\
\hline
\end{tabular}

Note. $\mathrm{N}=149$. Correlations are significant at $\mathrm{p}<0.01$, two-tailed.

\section{Use of data from the English Lexicon Project}

One objective of this study is to understand the role of word stress representations during cognate and non-cognate naming. To allow a comparison with native speaker performance, we analyzed the English L1 naming latency data 
in the English Lexicon Project (ELP) (Balota et al., 2007). The ELP includes naming aloud times for English words by 400 native speakers of $\mathrm{AE}$ (mean age: 23.5 years). From the ELP, we extracted naming latencies, standard deviations, and mean accuracies for the 100 test and filler words selected for our study (see Table 2).

Table 2. Word naming reaction times for each word category of English as L1, including mean RTs Standard Deviations (SD), and Accuracy (proportion) in each word category. Data from ELP (Balota et al., 2007).

\begin{tabular}{llll}
\hline \multicolumn{4}{l}{ Disyllabic words } \\
\hline Word status & RT $(\mathrm{ms})$ & SD & Accuracy \\
\hline Cognates & 633 & 45 & .98 \\
Non-cognates & 624 & 61 & .99 \\
Difference & 9 & & \\
\hline
\end{tabular}

Note. Cognates = cognates in English and Portuguese; non-cognate $=$ non-cognates in English and Portuguese; words are stressed on the pre-final syllable in English L1.

A Multiple Regression Analysis was performed in R ( $\mathrm{R}$ Development Core Team, 2011) on these AE RTs as an independent variable and Number of Syllables and Cognate Status as dependent variables. Because monolingual native speakers, in principle, should not be affected by Portuguese word properties, Cognate Status should not affect native naming latencies. Indeed, neither Cognate Status nor Number of Syllables turned out to be a significant predictor of naming latencies by monolingual English participants (p's > .1). Because of stimulus selection problems, we decided to use the trisyllabic words only as fillers in the experiments to be reported. The fillers were included to counter strategy effects with respect to word stress processing that might arise if only words of two syllables occur in the experiment.

\section{Experiment 1: Portuguese-English bilinguals naming mixed Portuguese and English words}

In a previous study (Post da Silveira et al., 2014), we tested how congruent or incongruent word stress affected the naming of cognate and non-cognate disyllabic words in Portuguese-English bilinguals. In that study, low frequency items were selected as stimuli from a database containing word stress positions for many English and Portuguese words. In an L2 word naming task, cognates with congruent stress were named slower than cognates with incongruent stress by $20 \mathrm{~ms}$, and non-cognates by $9 \mathrm{~ms}$. This finding suggests that during bilingual reading, L2 cognates (and perhaps non-cognates) activate competing lexical representations in L1 and L2. However, this interpretation was tentative, because the items did not show a cognate facilitation effect in the first place. This complicates the interpretation of the observed word stress effect. In addition, many previous studies have reported cognate facilitation effects in visual and 
auditory lexical decision (e.g., Dijkstra et al. 1999, 2002, 2010) and in lexical production (e.g., Costa \& Santesteban, 2004; Costa, Santesteban, \& Caño, 2005). Our tentative explanation for the absence of this cognate effect was that variability in responses (and relatively low percentage correct) due to the low frequency of the tested words diluted the cognate effect.

These observations make it important to reconsider the effect of crosslinguistic word stress on L2 word naming in this study. In Experiment 1, we therefore replicated the earlier study with two improvements in stimuli and design. First, we selected a set of items with a moderate frequency of occurrence, in the range of 10 to 70 occurrences per million. This allowed an easier selection of stimulus items and a broader generalization of conclusions. Furthermore, we examined both L1 and L2 naming by putting the target words in mixed (English and Portuguese) lists of words, requiring frequent language switching. We hypothesized that, because L1 is the participants' early and dominant language, the presence of L1 word stress patterns in a stimulus list might affect L2 word naming. Language switching effects due to the mixed list might result in significantly slower responses to cognates with incongruent stress between the two languages than cognates with congruent stress. For congruent cognates relative to congruent non-cognates, two outcomes are possible: a cognate facilitation effect (based on the available literature), or a cognate inhibition effect due to severe lexical competition caused by form and meaning overlap (see Gaskell \& Marslen-Wilson, 1997, 1999, 2001). In contrast, because the noncognates have different form representations in the two languages, we expected small or no effects of L2 word stress for non-cognates. If any effects would occur (e.g., inhibition for incongruent vs. congruent non-cognates), they could be ascribed mostly to effects of sublexical L2 word stress representation, because L2 non-cognates have fewer lexical associations with L1 translation neighbors (they do not share orthographic and phonological form similarities); here the Word Frequency of the L2 input is important for learning L2 word stress.

\section{Participants}

Fifteen BP native speakers (5 males and 10 females), all advanced learners of English as a second language, participated in Experiment 1. They were all recruited via LUCL labs. The mean age of the participants was 26.3 years (SD = 5.9). They reported their proficiency in English in a pre-test questionnaire. Participants who were selected graded equal to 90 or above according to TOEFL scores (Mean TOEFL Scores $=93.5, \mathrm{SD}=6.2$ ). They were all native BP speakers who learned English as a second language in adolescence. Three participants mentioned having lived in countries where English is the native language, but only in adulthood. During the experiment, they were living in the Netherlands, where their first language of communication was English. They reported not to study or speak the Dutch language. Furthermore, their scores in the X_Lex 2.05 English vocabulary test (Meara \& Milton, 2006) ranged between 3,500 and 4,900 points out of a maximum of 5,000 points (Mean $=3,947$ points, $\mathrm{SD}=413$ ), which rates 
them as upper intermediate to advanced learners of English. Participation was paid or voluntary. No participant reported having speech or hearing impairments and all had normal or corrected to normal vision.

\section{Design}

In this mixed word naming experiment, the target words were EnglishPortuguese translation pairs of two syllables that matched concerning their cognate status (cognate, non-cognate) and stress pattern (congruent on the pre-final syllable in L1 and L2 or incongruent - L1 pre-final syllable and L2 final syllable). Thus, a $2 \times 2$ design was created for the targets in each language, involving 4 stimulus categories per lexicon (English and Portuguese), as shown in Table 3. For both English and Portuguese, each of the four disyllabic word categories consisted of 15 stimuli selected from the bilingual corpus. In addition, 40 trisyllabic words with similar characteristics were chosen as fillers for each language. This resulted in a total of 200 stimulus words to be named by each participant.

Table 3. Stimulus categories used in word naming Experiment 1.

\begin{tabular}{|c|c|c|c|}
\hline $\begin{array}{l}\text { Word } \\
\text { Category }\end{array}$ & $\begin{array}{l}\text { Cognate } \\
\text { Status }\end{array}$ & $\begin{array}{l}\text { Stress } \\
\text { Congruence }\end{array}$ & Lexicon Examples \\
\hline 1 & Cognates & Congruent & $\begin{array}{l}\text { English cycle } \\
\text { Portuguese ciclo }\end{array}$ \\
\hline 2 & & Incongruent & $\begin{array}{l}\text { English billion } \\
\text { Portuguese bilhão }\end{array}$ \\
\hline 3 & Non-cognates & Congruent & $\begin{array}{l}\text { English oven } \\
\text { Portuguese forno }\end{array}$ \\
\hline 4 & & Incongruent & $\begin{array}{l}\text { English } \\
\text { Portuguese }\end{array}$ \\
\hline
\end{tabular}

Note. English words were taken from CELEX and Brazilian Portuguese words from NILC/Sao Carlos and ASPA corpora. Underlined syllables in the examples are stressed.

\section{Procedure}

The list of English and Portuguese target words was randomized per participant and divided into four experimental parts separated by a small break. The experiment was presented using E-Prime 2.0 software on a PC $(22050 \mathrm{~Hz})$ at LUCL labs. Words were presented in black at the center of the screen for 500 $\mathrm{ms}$, preceded by a $250 \mathrm{~ms}$ fixation cross (+). Participants read the word aloud as quickly and as accurately as possible. After $2 \mathrm{~s}$ the word disappeared and another trial began. Speech was recorded by a Sennheiser MKH-416 microphone and stored for later analysis. Each session lasted about 10 minutes. The experiment was preceded by a practice block of 20 English and 20 Portuguese words. 


\section{Results}

Response times were measured as the delay between stimulus onset and onset of speech production. Individual word productions were annotated applying a Praat script (Boersma \& Weenink, 2001) that subtracted the onset of the phonetic realization of the word in each trial from the tier beginning at the $0 \mathrm{~ms}$ of the onscreen presentation of the word. This procedure was applied to prevent data loss with voice-key devices. ${ }^{2}$ The resulting utterance onset times will be referred to as reaction times (RTs).

With respect to the stress pattern of each stimulus word, three judges, native speakers of American English, labeled all English production data from nonnatives in terms of word stress assigned to the first, second, or third syllable. The judges were 2 males and 1 female post-graduate students, with a mean age of 28 years (range between 24 and 30). A native speaker of BP, female, 30 years old, labeled the BP productions. The judges assessed whether stress assignment was perceived on the first, second, or third syllable position (in the case of trisyllabic filler words). Their judgment was later compared with canonical stress assignment of the words (based on corpus information about word stress). If their judgment matched with canonical stress, the tokens were considered correct responses. Overall, errors in Experiment 1 constituted 17.3\% (520 errors) of the 3,000 tokens. In total, 292 errors were made to L2 English disyllabic words, constituting 32\% of the 900 disyllabic words. From these errors, 43 (2.9\%) counted as unproduced words (absent or partially produced) and the other $29 \%$ were errors relative to stress assignment. Errors in L2 English trisyllabic words, which were filler items in this experiment, added up to 196 tokens (also 32\% from the 600 trisyllabic items). There were few errors in BP L1 productions: 32 tokens from 1500 tokens were wrong or not produced (2\%), 27 tokens in disyllabic words, and 5 tokens in trisyllabic words. The pattern of errors observed in various word categories is shown in Table 4.

Table 4. Number and proportion of word stress errors for each English (L2) word category.

\begin{tabular}{|c|c|c|c|c|}
\hline \multirow[b]{2}{*}{$\begin{array}{l}\text { Disyllabic } \\
\text { words }\end{array}$} & \multicolumn{2}{|l|}{ Congruent } & \multicolumn{2}{|c|}{ Incongruent } \\
\hline & $\begin{array}{l}\text { Absolute } \\
\text { Numbers }\end{array}$ & Proportion & $\begin{array}{l}\text { Absolute } \\
\text { Number }\end{array}$ & Proportion \\
\hline Cognates & 69 & .30 & 109 & .48 \\
\hline Non-cognates & 62 & .28 & 52 & .23 \\
\hline
\end{tabular}

Note. There were a total of 225 words per category.

Because in both $\mathrm{BP}$ and $\mathrm{AE}$, word stress is generally put on the penultimate syllable, errors on disyllabic words were expected to appear only in final syllable stress position. As Table 4 attests, this was indeed the case. Disyllabic words only had errors with respect to final syllable stress and an overall percentage of stress assignment errors of $32 \%$. In Table 4, we also see that cognates led to the largest 
number of errors when word stress was incongruent between the L2 target and an L1 competitor word.

To obtain further insights into these data, a Two-way Logistic Regression Analysis was performed with R lmr4 Package (Bates, Maechler, Bolker \& Walker, 2015) in which Accuracy of disyllabic words was a dependent binomial variable (correct or wrong), and Cognate Status and Stress Congruence across L1 and L2 were independent factors.

Table 5. Two-way Logistic Regression testing the influence of Cognate Status and Stress Congruence on word stress accuracy in word naming.

\begin{tabular}{lcccc}
\hline & Estimate & SE & $\mathrm{z}$ & $\mathrm{p}$ \\
\hline (Intercept) & 2.34 & 0.72 & 3.24 & $<.01$ \\
Cognate Status & -0.80 & 0.46 & -1.73 & .08 \\
Stress Congruence & -1.67 & 0.45 & -3.72 & $<.01$ \\
Cognate Status ${ }^{*}$ Stress Congruence & 0.95 & 0.29 & 3.25 & $<.01$ \\
\hline
\end{tabular}

As shown in Table 5, there was a highly significant main effect of Stress Congruence between L1 and L2 on accuracy. Although Cognate Status did not become significant as a main effect, a significant interaction arose between Cognate Status and Stress Congruence of Portuguese and English words.

Table 6 provides the mean word naming RTs for English as L2 and Portuguese as L1. Outlier RTs below $400 \mathrm{~ms}$ and above $1000 \mathrm{~ms}$ were excluded; from the total of 1800 tokens, 1743 tokens remained for analysis. Mean RTs for 3-syllable fillers were $585 \mathrm{~ms}(\mathrm{SD}=105$, Accuracy $=.77)$ for English (L2) and $572 \mathrm{~ms}(\mathrm{SD}=88$, Accuracy $=.99$ ) for Portuguese (L1). Accuracy did not reach $100 \%$, because of some errors unrelated to word stress assignment, like target words that were read as another word or that were not named at all. The RT data for English as an L2 can be compared to those in Table 2, based on the ELP for American English as L1. Table 7 provides the same data as Table 6, but instead of ignoring stress errors in L2 production (as in Table 6), it takes them into account (hence, the lower accuracies in L2). As can be seen, the general data pattern in both Tables is comparable.

Table 6. Mean reaction times (milliseconds, ms), Standard Deviations (SD), and Accuracy (proportion) per target language in the word categories of Experiment 1, ignoring stress errors in L2 production of disyllabic words.

\begin{tabular}{|c|c|c|c|c|c|c|}
\hline \multicolumn{7}{|c|}{ Experiment 1 (mixed word naming by bilinguals) } \\
\hline \multicolumn{2}{|c|}{ English (L2) } & \multirow[b]{2}{*}{ Incongruence } & \multirow[b]{2}{*}{ Dif. } & \multicolumn{2}{|c|}{ Portuguese (L1) } & \multirow[b]{2}{*}{ Dif } \\
\hline Word stress & Congruence & & & Congruence & Incongruence & \\
\hline \multicolumn{7}{|l|}{ Cognates } \\
\hline $\mathrm{RT}(\mathrm{ms})$ & 592 & 613 & -21 & 604 & 647 & -43 \\
\hline SD & 81 & 94 & & 92 & 131 & \\
\hline Accuracy & .96 & .98 & & .98 & .97 & \\
\hline \multicolumn{7}{|c|}{ Non-cognates } \\
\hline $\mathrm{RT}(\mathrm{ms})$ & 628 & 630 & -2 & 596 & 610 & -14 \\
\hline
\end{tabular}




\begin{tabular}{lllll} 
SD & 103 & 109 & 84 & 97 \\
Accuracy & .99 & .95 & .99 & .98 \\
RT difference & -36 & -17 & 7 & 37 \\
\hline
\end{tabular}

Note. Congruence $=$ word stress pattern is congruent on pre-final syllable in L1 and L2; Incongruence $=$ word stress pattern is incongruent, with L2 pre-final syllable stress and L1 final syllable stress. Dif. $=$ RT difference between congruent and incongruent stress conditions.

Table 7. Mean reaction times (milisseconds, ms), Standard Deviations (SD), and Accuracy (proportion) per target language in the word categories of Experiment 1 , taking into account stress errors in L2 production.

\begin{tabular}{|c|c|c|c|c|c|c|}
\hline \multicolumn{7}{|c|}{ Experiment 1 (mixed word naming by bilinguals) } \\
\hline & \multicolumn{2}{|l|}{ English (L2) } & \multirow[b]{2}{*}{ Dif. } & \multicolumn{2}{|c|}{ Portuguese (L1) } & \multirow[b]{2}{*}{ Dif. } \\
\hline 2-syll & Congruence & Incongruence & & Congruence & Incongruence & \\
\hline \multicolumn{7}{|l|}{ Cognates } \\
\hline $\mathrm{RT}(\mathrm{ms})$ & 585 & 610 & -25 & 600 & 640 & -40 \\
\hline SD & 87 & 91 & & 87 & 127 & \\
\hline Accuracy & .70 & .62 & & .98 & .97 & \\
\hline \multicolumn{7}{|c|}{ Non-cognates } \\
\hline $\mathrm{RT}(\mathrm{ms})$ & 624 & 636 & -12 & 596 & 607 & -11 \\
\hline $\mathrm{SD}$ & 103 & 113 & & 84 & 94 & \\
\hline Accuracy & .72 & .77 & & .99 & .98 & \\
\hline Dif. & -39 & -26 & & 4 & 33 & \\
\hline
\end{tabular}

Note. Congruence $=$ word stress pattern is congruent on pre-final syllable in L1 and L2; Incongruence $=$ word stress pattern is incongruent with L2 pre-final syllable stress and L1 final syllable stress. Dif.= RT difference between congruent and incongruent stress conditions.

Tables 6 and 7 show considerable facilitation for cognates in non-native English naming, but inhibition in native Portuguese naming, especially when English word stress was incongruent. To clarify the RT-patterns, a Multiple Regression Analysis was run in R on the word naming data of Table 7 with Target Language (Portuguese and English), Cognate Status, and Stress Congruence in L1 and L2 as three independent factors.

Table 8. Multiple Regression Analysis on RTs from the productions of Brazilian Portuguese L1 and English L2 target words by the same speakers.

\begin{tabular}{lllll}
\hline & Estimate & SE & $\mathbf{t}$ & $\mathbf{p}$ \\
\hline (Intercept) & 0.615 & 0.003 & 227.17 & $<.01$ \\
Target Language & -0.001 & 0.003 & -0.27 & .79 \\
Cognate Status & 0.001 & 0.003 & 0.39 & .70 \\
Stress Congruence & 0.010 & 0.003 & 3.71 & $<.01$ \\
Target Language * Cognate Status & -0.012 & 0.003 & -4.52 & $<.01$ \\
Target Language * Stress Congruence & 0.004 & 0.003 & 1.57 & .12
\end{tabular}




\begin{tabular}{lllll} 
Cognate Status ${ }^{*}$ Stress Congruence & -0.006 & 0.003 & -2.23 & .03 \\
$\begin{array}{l}\text { Target Language }{ }^{*} \text { Cognate Status* } \\
\text { Stress Congruence }\end{array}$ & -0.001 & 0.003 & -0.51 & .61 \\
\hline
\end{tabular}

Table 8 shows a main effect of Stress Congruence, but no main effects of Target Language (BP L1 or AE L2, produced by the same speakers) or Cognate Status was found. This indicates that overall responses for L1 and L2 produced by the same bilinguals did not differ in speed. Furthermore, significant interactions were found between Target Language and Cognate Status, and between Cognate Status and Stress Congruence, as well as a trend towards an interaction between Target Language and Stress Congruence.

To test which factors affected the RTs in each target language of Experiment 1 separately, we performed two language-specific Multiple Regression Analyses, shown in Tables 9 and 10.

Table 9. Multiple Regression Analysis on the RTs of bilingual speakers producing American English as L2 in Experiment 1.

\begin{tabular}{lllll}
\hline & Estimate & $\mathrm{SE}$ & $\mathbf{t}$ & $\mathbf{p}$ \\
\hline (Intercept) & 0.62 & 0.004 & 165.98 & $<.01$ \\
Cognate Status & 0.01 & 0.004 & 3.58 & $<.01$ \\
Stress Congruence & 0.01 & 0.004 & 1.57 & .12 \\
Cognate Status ${ }^{*}$ Stress Congruence & -0.01 & 0.004 & -1.26 & .21 \\
\hline
\end{tabular}

Table 10. Multiple Regression Analysis on the RTs of bilingual speakers producing Brazilian Portuguese as L1 in Experiment 1.

\begin{tabular}{lllll}
\hline & Estimate & SE & t & p \\
\hline (Intercept) & 0.614278 & 0.004 & 155.658 & $<.01$ \\
Cognate Status & -0.011178 & 0.004 & -2.832 & $<.01$ \\
Stress Congruence & 0.014300 & 0.004 & 3.623 & $<.01$ \\
Cognate Status* & & & & \\
Stress Congruence & -0.007428 & 0.004 & -1.882 & .06 \\
\hline
\end{tabular}

In L2 AE, the only significant main effect was found for Cognate Status (see Table 9). In L1 BP, RTs were affected significantly by Cognate Status and Stress Congruence, while the interaction between Cognate Status and Stress Congruence was close to significance (see Table 10). Welch Two Sample T-tests showed that in L1 BP, RTs were significantly affected by the Stress Status of cognates $(\mathrm{t}(301.14)=-3.54, \mathrm{p}<.01)$, but not that of non-cognates $(\mathrm{p}>.05)$. When word stress was congruent, there was no effect of Cognate Status ( $p>.05)$; but when word stress was incongruent, Cognate Status affected RT significantly $(\mathrm{t}(309.71)=2.98, \mathrm{p}<.01)$. 


\section{Discussion}

In Experiment 1, Portuguese-English bilinguals named English and Portuguese words in a mixed list. The targets consisted of disyllabic words that were cognates or non-cognates in English and Portuguese. They bore stress on the penultimate syllable, and this stress could be congruent or incongruent across English and Portuguese. In the L2 incongruent conditions, word stress was on the ultimate syllable of the non-target language, BP. Table 4 showed a complex but systematic pattern in RTs and accuracy that depended not only on cognate status and congruence of word stress, but also on the item's language (AE or BP).

First, items in English (L2) were named with low accuracy. Inspection of the errors by the bilinguals indicates that the inaccurate items were largely correct segmentally but produced with a deviating word stress (25.3\%). In these cases, word naming led to stress on the ultimate syllable (20\%), suggesting effects of the non-target language (L1, Portuguese) on pronunciation. The disyllabic words only had ultimate syllable stress as error pattern - and suffered from a high percentage of such stress errors (38\%). The reduction of naming accuracy was stronger for cognates than for non-cognates, and also numerically stronger for cognates with incongruent stress relative to congruent stress. These effects can be attributed to interlingual lexical competition in the cognate pairs, including word stress. When comparing the effect of errors on the RT-patterns of each word category, Table 6 (including stress errors) and Table 7 (excluding stress errors) showed no clear effects on RT-patterns. This suggests that speakers were not aware of stress assignment issues in the naming task they were performing and that they were responding based on a mixed L1 and L2 representation of word stress. The data suggest that the dominant system responding for the word stress production in this task was L1, because L1 word stress assignment was highly accurate and the low accuracy of L2 word stress assignment did not cause faster RTs. This result is supported by other empirical studies on bilingual word stress production from orthography, such as Primativo et al. (2013) and Bellocchi et al. (2016), who reported dominance effects of L1 word stress on L2 word naming by ItalianEnglish bilinguals. The use of L1 word stress regularities on L2 word stress word naming results from processing L1 and L2 mixed representations of word stress.

For non-cognates, we observed only non-significant incongruence effects on English (L2) naming (see Table 7). Thus, the English non-cognate words were insensitive to whether word stress in $\mathrm{AE}$ and $\mathrm{BP}$ was congruent or not, even though the list mixed English and Portuguese items. In all, no generalized effect of L1 word stress assignment was found for non-cognates.

Importantly, English (L2) cognates in congruent conditions were named faster than non-cognates. Such L2 cognate facilitation was expected on the basis of previous studies in comprehension and production (Dijkstra 1999; Smits et al., 2006; Smits, 2009). It suggests that the absence of a cognate facilitation effect in an earlier study (see Post da Silveira et al., 2014) was due to the low frequency of target items in that study. As was also expected, the size of this cognate effect was 
reduced in incongruent word stress conditions. Apparently, two cognate readings that are incongruent in word stress for English and Portuguese are in stronger competition, making the auditory lexical decision more difficult.

In line with other cognate reading studies (e.g., Costa \& Santesteban, 2004, Costa et al 2005; Smits et al., 2006, 2009), the patterns of cognate naming in Portuguese (L1) and English (L2) were different. Instead of a cognate facilitation effect, a cognate inhibition effect was found in L1. Thus, under these mixed experimental conditions, the naming of Portuguese L1 words suffered from the presence of English L2 words. This indicates that in the present experiment both Portuguese and English were activated and competed.

We note that in English, incongruent items bore stress on the penultimate syllable, while their counterpart translation words in BP bore stress on the ultimate syllable. Because the effect of stress incongruence arose in L1 cognates alone, the observed inhibition effect cannot simply be ascribed to a slower processing of word stress on the ultimate syllable of polysyllabic words relative to earlier syllable positions (cf. Meyer, 1990, 1991). Under this assumption, we would have expected to find slower RTs for L1 non-cognates with incongruent stress as well.

In sum, Experiment 1 resulted in both cognate effects and word stress effects depending on target language (L1 or L2). Because naming accuracy in some conditions was low (because participants used their L1 representation as default), it is important to check if the general RT-patterns can be replicated or even strengthened under different task conditions. In Experiment 2, we therefore had participants name the same English target words as before, but we primed the items with auditory primes from Portuguese. The primes were translation equivalents of the targets (in the case of cognates), unrelated to the target, or non-linguistic in nature.

\section{Experiment 2: Portuguese-English bilinguals naming English words preceded by auditory Portuguese primes}

In Experiment 2, bilinguals named L2 cognates and non-cognates preceded by auditory primes. In these experimental circumstances, the physically present word stress pattern of the auditory prime can exert a more direct effect on the naming of the visually presented target item. We expected that auditory L1 primes that share more phonetic-phonological and meaning aspects with L2 targets (cognates or non-cognates) exert a larger L1 word stress effect than primes that are dissimilar.

To assess how target word processing is affected by a prime, we included three different conditions. First, we included a test condition in which the prime was the translation of the target. Here, the prime was different in form in the non-cognate condition, and similar in form in the cognate condition (where it was the other-language counterpart of the target cognate), and it was either stress congruent or incongruent with the L2 target. Three predictions were made for this translation condition. First, semantic overlap between non-cognate primes 
and targets should result in facilitation relative to the unrelated condition. Next, although the cognate primes and targets also share their meaning, they should suffer from additional lexical competition due to form overlap. As a consequence, cognates in this test condition should be named slower than matched noncognates. Finally, on the basis of lexical form competition we also predicted slower RTs to cognates in the translation condition than in the unrelated condition.

Second, we incorporated a control condition with an unrelated word prime. This condition might be expected to result in RT-patterns for targets similar to those in Experiment 1, i.e., cognate facilitation effects. The stress pattern of the prime was matched to that of the target, which could result in additional facilitation.

Third, as another baseline we added a control prime consisting of babble noise. Such noise might result in some fluctuation of the activation of word candidates and might affect the degree of competition / facilitation of activated cognate and non-cognate targets. Since the use of babble noise is original to this study, this prediction is exploratory.

\section{Participants}

Fifteen BP native speakers ( 7 males and 8 females), all advanced learners of English as a second language, who did not participate in Experiment 1, participated in Experiment 2. The mean age of the participants was 23.8 years (range: $21-28, \mathrm{SD}=2.5$ ). Participants all indicated to be monolingual BP speakers who learned English as a second language in adolescence. Four participants mentioned having lived in countries whose native language is English, but only in adulthood. During their participation in the experiment, they were living in The Netherlands for a short term (often for exchange programs) and their first language of communication was English. Furthermore, their scores in the $\mathrm{X}_{-}$ Lex2.05 English vocabulary test (Meara \& Milton, 2006) ranged between 4,050 and 4,950 points out of a maximum of 5,000 points, rating them as advanced learners. Participation was paid or voluntary.

\section{Stimulus Materials}

Participants named in total 300 visually presented items. These consisted of 100 different English targets preceded by 100 Portuguese primes (see above). Each target word was presented three times: preceded by a form and meaning unrelated prime with congruent or incongruent word stress, and a nonword prime consisting of babble noise. The stimuli were distributed across 4 blocks of 75 items, counterbalanced with respect to prime-target conditions. Stimuli were differently randomized for each participant.

\section{Design}

The visual targets were always English L2 disyllabic words that bore penultimate stress. Three conditions were generated by adding auditory Portuguese L2 primes to these targets. The Translation condition included L1 translation primes that were either phonetically-phonologically similar (cognates) 
or dissimilar (non-cognates) to the targets. Word stress could be either congruent on the penultimate syllable or incongruent on the ultimate syllable relative to the target. The Unrelated condition included L1 primes that were different in meaning and segmental sequence to the L2 targets, but coincided in number of syllables, and stress congruence or incongruence. The average duration of disyllabic primes was 670 milliseconds (ms) and of trisyllabic words was $900 \mathrm{~ms}$. Finally, the Babble Noise condition was a control condition that consisted of two non-linguistic babble noise types created from the addition of 100 streams of disyllabic BP words. These streams had originally been uttered by a female native BP speaker. The pitch contours of the babble stimuli were monotonized (no pitch peaks) at the average of the speaker (ble ) and had duration of $607 \mathrm{~ms}$ or 900 $\mathrm{ms}$ for disyllabic or trisyllabic babble noises, respectively. The target and prime categories are exemplified in Table 11.

Table 11. Test conditions in Experiment 2.

\begin{tabular}{lllll}
\hline Target status & $\begin{array}{l}\text { Stress Target L2 vs. L1 } \\
\text { Stress Prime }\end{array}$ & $\begin{array}{l}\text { Translation } \\
\text { condition }\end{array}$ & $\begin{array}{l}\text { Unrelated } \\
\text { condition }\end{array}$ & $\begin{array}{l}\text { Babble Noise } \\
\text { condition }\end{array}$ \\
\hline $\begin{array}{l}\text { English } \\
\text { Cognates }\end{array}$ & Congruent & $\begin{array}{l}\text { NOBLE } \\
\text { (nobre) }\end{array}$ & $\begin{array}{l}\text { NOBLE } \\
\text { (seta) }\end{array}$ & $\begin{array}{l}\text { NOBLE } \\
(-----)\end{array}$ \\
& Incongruent & $\begin{array}{l}\text { SIGNAL } \\
(\text { sinal) }\end{array}$ & $\begin{array}{l}\text { SIGNAL } \\
\text { (refrão) }\end{array}$ & $\begin{array}{l}\text { SIGNAL } \\
(-----)\end{array}$ \\
$\begin{array}{l}\text { English } \\
\text { Non-cognates }\end{array}$ & Congruent & $\begin{array}{l}\text { ARROW } \\
\text { (seta) }\end{array}$ & $\begin{array}{l}\text { ARROW } \\
\text { (nobre) }\end{array}$ & $\begin{array}{l}\text { ARROW } \\
(-----)\end{array}$ \\
& Incongruent & $\begin{array}{l}\text { CHORUS } \\
\text { (refrão) }\end{array}$ & $\begin{array}{l}\text { CHORUS } \\
\text { (sinal) }\end{array}$ & $\begin{array}{l}\text { CHORUS } \\
(-----)\end{array}$ \\
\hline
\end{tabular}

Note. Congruence $=$ word stress pattern congruent in L1 and L2; Incongruence $=$ word stress pattern incongruent in L1 and L2. The examples for each condition show primes (in lower-case letters or dashes in parentheses) and targets (in upper-case letters).

\section{Procedure}

The experiment was programmed using E-Prime 2.0 software. Each participant performed the experiment individually in a noise-poor experimentation booth. Participants were seated in front of a computer screen at a distance of $60 \mathrm{~cm}$. At the center of the screen, upper-case word stimuli appeared in black font, type Arial and size 18 (resolution: 1024x768 pixels). Each trial started with a fixation cross (+) of $250 \mathrm{~ms}$, followed by an English target word for $500 \mathrm{~ms}$. Simultaneous with this target, participants heard the Portuguese word prime spoken by a female native speaker or the babble noise through their headphones. Participants had a $1500 \mathrm{~ms}$ interval to name the target after it disappeared from screen and a new trial began. A Sennheiser MKH-416 microphone linked directly to a PC 
$(22,050 \mathrm{~Hz})$ was used to capture the participants' speech. E-Prime 2.0 recorded and stored their speech productions for later analysis. Each session lasted, on average, 15 minutes. The actual experiment was preceded by a training phase that followed the same dynamics as the actual experiment, but consisted of 24 English targets preceded by $24 \mathrm{BP}$ primes not included in the experiment proper.

\section{Results}

Using the same methodology as Experiment 1, RTs were obtained by annotating word productions and subtracting the onset of word production from the start of visual stimulus presentation.

According to the judgment of the American English native speakers, stress assignment errors amounted to 210 tokens, or $4.7 \%$, on a total of 4,500 tokens. The data for disyllabic words totalled 2,700 tokens. A Three-way Logistic Regression was run in $\mathrm{R}$ on the disyllabic accuracy data, with Cognate Status, Stress Congruence in L1 and L2, and Prime Condition as independent variables. As shown in Table 12, errors in disyllabic word naming were caused in majority by stress incongruence across languages.

Table 12. Two-way Logistic Regression testing the influence of Cognate Status and Stress Congruence across L1 and L2 on word stress accuracy in speech production.

\begin{tabular}{lllll}
\hline & Estimate & SE & $\mathrm{z}$ & $\mathrm{p}$ \\
\hline (Intercept) & 47.79 & .68 & 7.02 & $<.01$ \\
Cognate Status & -0.17 & .27 & -0.63 & 0.53 \\
Stress Congruence & -0.66 & .27 & -2.42 & 0.02 \\
Prime Condition & 0.17 & .12 & 1.40 & 0.16 \\
\hline
\end{tabular}

In Table 13, we present the naming data for disyllabic words as dependent on Stress Congruence, Cognate Status, and Prime Condition.

Table 13. Reaction times per language and word conditions of Experiment 2 including mean RTs, Standard Deviations (SD) and accuracy percentage (Accuracy) of word stress assignment in each condition.

\section{Experiment 2 (English L2 word naming with Portuguese L1 primes}

\begin{tabular}{lllllllll}
\hline & \multicolumn{2}{l}{ Translation } & & \multicolumn{2}{l}{ Unrelated } & & Babble noise \\
\cline { 2 - 3 } & Congr. & Incongr. & Dif. & Congr. & Incongr. & Dif. & Control \\
\hline Cognate & & & & & & & & \\
RT (ms) & 601 & 600 & 1 & 542 & 533 & 9 & 511 \\
SD & 106 & 138 & & 122 & 118 & & 128 \\
Accuracy & .99 & .97 & & .98 & .98 & & .99 \\
Non-cognate & & & & & & & & \\
RT (ms) & 539 & 559 & -20 & 620 & 601 & 19 & 497 \\
SD & 119 & 119 & & 123 & 130 & & 127
\end{tabular}




\begin{tabular}{cccccc} 
Accuracy & .99 & .97 & .99 & .98 & .96 \\
RT difference & 62 & 41 & -78 & -68 & 14 \\
\hline
\end{tabular}

Note. Translation prime $=$ BP $(\mathrm{L} 1)$ prime has same meaning, similar or dissimilar phonology, and congruent or incongruent stress pattern as L2 target; Unrelated prime $=\mathrm{BP}$ (L1) prime differs from L2 target in phonology and meaning, and is congruent or incongruent in stress pattern with L2 target; Babble Noise prime = non-linguistic babble noise with similar duration length of the L2 target. Dif. = RT difference between congruent and incongruent stress conditions.

Overall, disyllabic target words were produced $22 \mathrm{~ms}$ slower $(561 \mathrm{~ms})$ than trisyllabic filler words $(539 \mathrm{~ms})$. Filler words were produced with an accuracy of $77 \%$ when they were from L2 (English) and of 98\% when they were from L1 (Portuguese).

We subsequently analyzed the RTs for different conditions. After excluding errors and outliers (RTs below $300 \mathrm{~ms}$ and above $1000 \mathrm{~ms}$ ), the remaining data consisted of 2,581 tokens. We investigated the factors affecting the RT-patterns of native speakers of Portuguese or English and compared them to L2 speakers of English. In a Multiple Regression model we tested how RTs were affected by Cognate Status, Stress Congruence, and Prime Condition.

Table 14. Multiple Regression analysis of the effects of Cognate Status, Stress Congruence, and Prime Condition by Brazilian Portuguese auditory primes on English target RTs.

\begin{tabular}{lllll}
\hline & Estimate & SE & t & p \\
\hline (Intercept) & 0.608 & 0.005 & 123.23 & $<.001$ \\
Prime Condition & -0.025 & 0.002 & -10.98 & $<.001$ \\
Cognate Status & -0.030 & 0.005 & -6.09 & $<.001$ \\
Stress Congruence & 0.006 & 0.005 & 1.20 & .23 \\
Prime Condition ${ }^{*}$ Cognate Status & 0.014 & 0.002 & 5.94 & $<.001$ \\
Prime Condition ${ }^{*}$ Stress Congruence & -0.001 & 0.002 & -0.22 & .83 \\
Cognate Status * Stress Congruence & 0.001 & 0.005 & 0.09 & .93 \\
Prime Condition ${ }^{*}$ Cognate Status * & & & & \\
Stress Congruence & -0.001 & 0.002 & -0.32 & .75 \\
\hline
\end{tabular}

Table 14 indicates that Cognate Status and Prime Condition led to significant main effects in this statistical model, while Stress Congruence resulted neither in a main effect nor in any interactions. Across conditions, cognates led to longer naming latencies than non-cognate words. However, Cognate Status also interacted with Prime Condition, reflecting a considerable inhibition of cognates in the Translation Condition, a large facilitation of cognates in the Unrelated Condition, and no effect in the Babble Condition.

To clarify this interaction, paired t-tests were done for each condition separately. In the Translation condition, the effect of Cognate Status (cognates or non-cognates) was significant $(\mathrm{t}(543)=-4.07, \mathrm{p}<.001)$, but the effect of Stress Congruence (congruent or incongruent word stress) was not $(\mathrm{p}>.05)$. 
In the Unrelated condition, the (opposite) effect of Cognate Status also reached significance $((t) 441)=2.05, \mathrm{p}<.04)$, but Stress Congruence did not $(\mathrm{p}>.05)$. In the Babble Noise condition, the $14 \mathrm{~ms}$ effect of Cognate Status did not reach significance $(\mathrm{p}>.05)$.

\section{Discussion}

In Experiment 2, Portuguese-English bilinguals named printed English words that were simultaneously presented with auditory primes. Because the word stress of the auditory prime was readily available, it could potentially directly affect target word naming. Although the experiment required naming only English target words, the actual presence of Portuguese auditory primes was assumed to lead to a larger influence of L1 in this experiment than in Experiment 1 without L2 primes in each trial. This conclusion is supported by the generally large size of the priming effects in Table 14.

Inspection of the data in Table 14 shows that, irrespective of other effects, the presence of the auditory word primes resulted in increased naming accuracies; in fact, responses in the babble noise condition were quite accurate. Closer inspection shows that, just like in Experiment 1, word stress congruence or incongruence between prime and target significantly affected the accuracy of target responses. This effect of word stress was not evident in the RTs, however. With respect to RTs, influential factors were Prime Condition and Cognate Status. Thus, the RTs were significantly affected by both target word characteristics and the specific relationship between prime and target, but not by Stress Congruence.

Next, we assessed the basic effect of auditory primes by means of a nonlinguistic control condition of babble noise. A small (14 ms) and non-significant inhibitory effect of this prime was found for cognates relative to non-cognates. Given the trend towards an effect, the general and item-specific effects of such primes deserve to be more closely examined in future research.

Furthermore, in the Unrelated prime condition, strong facilitation effects arose for disyllabic cognates relative to non-cognates, but there were no clear Stress Congruence effects. The cognate facilitation effect in the Unrelated prime condition is most comparable to the single-word naming results of Experiment 1. In fact, cognate facilitation was much larger here than in Experiment 1. Two possible reasons are that the prime reduced the activation of other competitors of the cognates, or that the auditory stimulus evoked additional arousal, facilitating responding (note that the presence of babble noise led to generally faster RTs). The effect of word stress (in)congruence on naming did not reach significance in the Unrelated prime condition.

The most complex condition in this experiment was that of English target words primed by their translations. For non-cognates, the meaning relationship between prime and target translations resulted in faster RTs than in the unrelated conditions. However, for cognates, the overlap in both meaning and form between prime and target resulted in a strong cognate inhibition effect. This finding is 
in line with the representation proposed for cognates in the visual modality (Dijkstra et al., 2010): An increase in form and meaning overlap should result in stronger activation of both cognate readings and increased lexical competition, because the prime is a competitor that is actually presented. This should result in a more difficult candidate selection process and slower RTs to the target (cf. Dijkstra et al., 2010).

\section{General discussion}

We investigated how word stress is represented in the lexicon of BP-AE bilinguals, and what role it plays in bilingual word naming. We examined whether cognate effects in L2 bilingual word naming are sensitive to the congruence or incongruence of L1 and L2 word stress.

In Experiment 1, for a mixed-list of BP-AE words, a cognate facilitation effect arose in the English (L2) word naming times of Portuguese-English bilinguals. This finding is in line with a view of language nonselective access to the bilingual lexicon. The hypothesis of co-activated representations from the two languages is further supported by the large number of L2 word stress naming errors that the bilinguals made. The errors often reflected the use of the word stress pattern from Portuguese (L1) instead of English (L2).

In English (L2), in addition to a cognate facilitation effect, there also was a trend towards an effect of Stress Congruence. Responses to English cognates were 21 ms slower when the cognates had different word stress in the two languages. Although the effect was statistically only suggestive, it appears that, similar to differences in phonological overlap (Dijkstra et al., 2010), differences in word stress can result in slower RTs (in addition, a clear effect of word stress was found in L1, see below). In the present study, this might be due to differences in the activation process underlying cognates with congruent and incongruent word stress. For instance, BP native speakers reading the English word master might not have decoded it as /'maes.tor/ but as /'mes.tr/. This would lead to a co-activation of L1 neighbours like medico /'me.di.ku/ ('physician') and Meca / 'me.ca/ ('Mecca'). In the case of master, there are many neighbours that share the stress position with the decoded word, which might facilitate word naming. This conclusion for L2 lexical phonological retrieval in naming is similar to that of L2 spoken word recognition studies (e.g., Cutler \& Weber, 2007; Weber \& Broersma, 2012). However, if the BP native speakers read the L2 word signal /'sig.nəl/, a cognate with the L1 word sinal /si 'naw/, the incongruence in word stress might result not only in less activation of sinal (leading to a smaller cognate facilitation effect), but also in the activation of other word candidates due to word stress differences (e.g., sino - which is a noun meaning 'bell' and an adjective meaning 'Chinese', pronounced as /'sinu/).

For Portuguese (L1), cognates were named slower rather than faster than non-cognates. This cognate inhibition effect was especially strong in the incongruent word stress condition: Incongruent cognates were named about 40 
$\mathrm{ms}$ slower than congruent cognates $(\mathrm{p}<.01)$. In other words, for $\mathrm{L} 1$ especially the combination of segmental overlap and incongruent word stress resulted in slower RTs. The dependence of the word stress effect on segmental overlap (as reflected by cognate status) indicates that word stress cannot be ignored by the participant when it is not beneficial for the naming response. In sum, cognate status and word stress (in)congruence combine their effects, resulting in an inhibition of L1 lexical activation. Because lexical stress affects cognate naming, it must be part of the L1-L2 phonological lexical representation. The cognate and word stress effects were found in the dominant language most likely because of a higher activation of words in L1 than in L2.

In Experiment 2, we again conducted a Portuguese-English naming task, but here auditory primes preceded the visual targets to be named. Importantly, the findings of Experiment 1 for isolated targets were confirmed in that cognates were processed considerably faster than non-cognates when both item types were preceded by unrelated auditory prime conditions. The effects of word stress congruence, however, were non-significant and opposite in direction (i.e., somewhat faster RTs were obtained in incongruent conditions). This was unexpected, because we predicted larger word stress effects on the basis that the primes had the same stress patterns as the targets; this could have facilitated target selection in the case of cognates.

Experiment 2 further allowed us to investigate the effects of semantic priming in non-cognates and cognates, also in relation to word stress (in)congruence. For non-cognates, translation primes led to considerable semantic facilitation: RTs were about $60 \mathrm{~ms}$ faster in the Translation prime condition than in the Unrelated condition. Interestingly, this facilitation effect turned into a similarly sized inhibition effect for cognates: Cognate naming was much slower when the cognates were preceded by their translation equivalents than by unrelated primes. Because cognates and non-cognates differ in form overlap with their other-language counterparts, this finding confirms visual studies that reported inhibition effects of orthographic form overlap (Dijkstra et al., 2010).

In Experiment 2, the effects of word stress (in)congruence on RT were nonsignificant. There was a significant effect on accuracy, but one must take into account that the number of naming errors was remarkably small relative to Experiment 1. Perhaps in the cognate condition, the actually present stress patterns of the auditory L1 prime made the participants more aware of a stress difference for the incongruent L2 target. Further research is necessary to investigate this possibility, because the prime condition with Babble Noise also suggests that auditory primes may subtly change the activation state in the bilingual lexicon (note that cognates and non-cognates were somewhat differently affected by Babble Noise).

The two experiments of this study consistently showed the presence of cognate effects in bilingual auditory processing. The analysis of word naming data in L2 and L1 clarified some of the mechanisms underlying cognate facilitation vs. cognate inhibition, for instance, in terms of L1-L2 lexical competition dependent on segmental overlap, L1-L2 suppression mechanisms, and word stress effects. 
Importantly, the experiments showed that during the retrieval of a word's stress pattern, the stress pattern of word candidates from another language may be coactivated and interfere with target production by slowing down RTs and inducing naming errors. This was especially the case for cognates, for which there is a direct and strongly activated competitor with form and meaning overlap. The stress incongruence effects in Experiment 1 were relatively large (25 to $40 \mathrm{~ms}$ ) and indicate that in a bilingual word naming task, word stress of items in two languages is activated and used on-line.

\section{Conclusions}

On the basis of these results, we conclude that bilingual word recognition and bilingual word production models cannot ignore the effects of word stress in their accounts. Because of the inherent link between segmental information and word stress, we propose that it is parsimonious to represent word stress in relation to phonological, rather than orthographic representations. With respect to the current study, this implies that the effects of word stress played their role when phonological representations became available as part of lexical retrieval and less so as part of sublexical decoding of phonology from orthography in L2 word naming. Future studies should test this view by manipulating task demands (e.g., collecting results in a task like lexical decision).

Finally, the present results (especially those from Experiment 1) suggest that L2 speakers possess a mixed L1-L2 system of word stress. For some lexical representations, they appear to apply word stress assignment rules from their L1, for others they use rules from their L2. On the one hand, this mixed system might make them more dependent on language-general word stress frequency distributions (determined by general sublexical properties), and on the other hand on lexical recognition and lexical phonology. As previous studies on word stress have shown, word stress regularities play a role when lexical frequency is low (Colombo, 1992; Protopapas, 2006ab; Perry, 2010), and, in case of bilinguals, other lexical effects may also be involved, such as competition with similar words from a stronger L1 phonological system. This 'messy' representational system must have consequences for other domains of processing than naming. For instance, it is likely that the bilinguals' $\mathrm{L} 2$ word recognition process is affected by different competitors than that from L1 speakers, and by the same competitors to a different degree due to activation differences.

Acknowledgements: I would like to specially thank my PhD supervisors, Prof. Dr. Ton Dijkstra and Prof. Dr. Niels O. Schiller, for their comments and suggestions on this paper and for their help and dedication along my $\mathrm{PhD}$ project. I am greatly thankful for the two grants I received for my $\mathrm{PhD}$ project: one from the Erasmus Mundus Program (Monesia Program) and another from CNPq (Conselho Nacional de Desenvolvimento Científico e Tecnológico). I also thank very much the technical and lab support and use of the labs at Leiden University Centre 
for Linguistics and the financial and lab support from the Donders Institute for Brain, Cognition and Behaviour.

\section{Notes}

1. Further details on the composition of this bilingual corpus can be found in Post da Silveira \& van Leussen (2015).

2. This Praat script was created by Jos Pacilly from Leiden University Centre for Linguistics

\section{References}

Baayen, R. H., Piepenbrock, R., \& van Rijn, H. (1993). The CELEX lexical database. Philadelphia, PA: Linguistic Data Consortium, University of Pennsylvania.

Balota, D. A., Yap, M. J., Cortese, M. J., Hutchison, K. A., Kessler, B., Loftis, B., Neely, J. H., Nelson, D. L., Simpson, G. B., \& Treiman, R. (2007). The English Lexicon Project. Behavior Research Methods, 39, 445-459.

Baptista, B. O. (2006). Adult phonetic learning of a second language vowel system. In B. Baptista and, M. Watkins (Eds.) English with a Latin Beat: Studies in Portuguese/ Spanish - English Interphonology (pp. 19-40). Amsterdam: John Benjamins.

Bates, D., Maechler, M., Bolker, B., \& Walker, S. (2015). Fitting Linear Mixed-Effects Models Using lme4. Journal of Statistical Software, 67(1), 1-48.

Bellocchi, S., Bonifacci, P., \& Burani, C. (2016). Lexicality, frequency and stress assignment effects in bilingual children reading Italian as a second language. Bilingualism: Language and Cognition, 19, 89-105.

Best, C. T. (1995). A direct realist perspective on cross-language speech perception. In: W. Strange (Ed.), Speech Perception and Linguistic Experience: Theoretical and Methodological Issues in Cross-language Speech Research (pp. 167-200). York: Timonium. MD.

Bion R. A. H., Escudero, P., Rauber, A. S., \& Baptista, B. O. (2006). Category formation and the role of spectral quality in the perception and production of English front vowels. Proceedings of INTERSPEECH, Pittsburgh, 1363-1366.

Bisol, L. (1992). O acento e o pé métrico binário. Cadernos de Estudos Linguísticos, 22, 69-80.

Boersma, P., \& Weenink, D. J. M. (2001). Praat, a system for doing phonetics by computer. Glot International, 5(9/10), 341-347.

Brysbaert, M., \& van Wijnendaele, I. (2003). The importance of phonological coding in visual word recognition: Further evidence from second-language processing. Psychologica Belgica, 43, 285-294.

Burani, C., \& Arduino, L. (2004). Stress regularity or consistency? Reading aloud Italian polysyllables with different stress patterns. Brain and Language, 90(1-3), 318-25.

Cantoni, M. M. (2008). O acento no português brasileiro segundo uma abordagem baseada no uso. Estudos Linguísticos, 38, 93-102.

Chateau, D., \& Jared, D. (2003). Spelling-sound consistency effects in disyllabic word naming. Journal of Memory and Language, 48(2), 255-280.

Clopper, C.G. (2002). Frequency of stress patterns in English: A computational analysis. Indiana University Linguistics Club Working Papers Online 2(2). Retrieved from: http://www.indiana.edu/ iulcwp 
Coltheart, M., \& Rastle, K. (1994). Serial Processing in Reading Aloud: Evidence for Dual-Route Models of Reading. Journal of Experimental Psychology: Human Perception and Performance, 20, 1197-1211.

Coltheart, M., Rastle, K., Perry, C., Langdon, R., \& Ziegler, J. (2001). DRC: A Dual Route Cascaded model of visual word recognition and reading aloud. Psychological Review, 108, 204-256.

Colombo, L. (1992). Lexical stress effect and its interaction with frequency in word pronunciation. Journal of Experimental Psychology: Human Perception and Performance, 18(4), 987- 1003.

Colombo L, \& Zevin, J. (2009) Stress Priming in Reading and the Selective Modulation of Lexical and Sub-Lexical Pathways. PLoS ONE, 4(9), e7219. doi:10.1371/journal. pone.0007219.

Costa, A., \& Santesteban, M. (2004). Lexical access in bilingual speech production: Evidence from language switching in highly proficient bilinguals and L2 learners. Journal of Memory and Language, 50, 491-511.

Costa, A., Santesteban, M., \& Caño, A. (2005). On the facilitatory effects of cognate words in bilingual speech production. Brain and Language, 94, 94-103.

Cristófaro-Silva, T., de Almeida, L. S., \& Fraga, T. (2005). ASPA: A Formulação de um Banco de Dados de Referência da Estrutura Sonora do Português Contemporâneo. Proceedings XXV Congress of Brazilian Society of Computing Science, São Leopoldo, RS, Brazil.

Cutler, A., \& Weber, A. (2007). Listening experience and phonetic-to-lexical mapping in L2. In J. Trouvain and W. J. Barry (Eds.), Proceedings of the 16th International Congress of Phonetic Sciences (ICPhS 2007) (pp. 43-48). Dudweiler: Pirrot.

de Groot, A. M. B.; Borgwaldt, S.; Bos, M.; van den Eijnden, E. (2002). Lexical Decision and Word Naming in Bilinguals: Language Effects and Task Effects. Journal of Memory and Language, 47(1), 91-124.

Dijkstra, A. (2007). Lexical Processing in Bilinguals and Multilinguals: The Word Selection Problem. The Multilingual Lexicon, 11-26.

Dijkstra, T., Grainger, J. \& van Heuven, W. J. B. (1999). Recognition of Cognates and Interlingual Homographs: The Neglected Role of Phonology. Journal of Memory and Language, 41, 496-518.

Dijkstra, T., Miwa, K., Brummelhuis, B., Sappelli, M., \& Baayen, H. (2010). How cross-language similarity and task demands affect cognate recognition. Journal of Memory and Language, 62(3), 284-301.

Dijkstra, A., \& van Heuven, W.J.B. (2002). The architecture of the bilingual word recognition system: From identification to decision. Bilingualism: Language and Cognition, 5, 175-197.

Flege, J. (1995). Second-language Speech Learning: Theory. Findings. and Problems. In W. Strange (Ed.). Speech Perception and Linguistic Experience: Issues in Crosslanguage research. Timonium. MD: York Press, 229-273.

Frost, R., Katz, L., \& Bentin, S. (1987). Strategies for visual word recognition and orthographical depth: A multilingual comparison. Journal of Experimental Psychology: Human Perception and Performance, 13, 104-115.

Frota, S., M. Vigário, Martins, F., \& Cruz, M. (2010). FrePOP - Frequency Patterns of Phonological Objects in Portuguese: Research and Applications (PTDC/ LIN/70367/2006) Faculdade de Letras da Universidade de Lisboa. ISBN: 978-98995713-2-7 
Gaskell, G. M., \& Marslen-Wilson, W. D. (1997), Integrating form and meaning: a distributed model of speech perception. Language and Cognitive Processes, 12, 613-656.

Gaskell, M. G., \& Marslen-Wilson, W. D. (1999). Ambiguity, competition and blending in spoken word recognition. Cognitive Science, 23, 439-462.

Gaskell, M. G., \& Marslen-Wilson, W. D. (2001). Lexical ambiguity and spoken word recognition: bridging the gap. Journal of Memory and Language, 44, 325-349.

Guion, S. (2001). Acquisition of English word stress patterns in early and late bilinguals. Journal of the Acoustical Society of America, 115, 2503-2503.

Jared, D. (2002). Spelling-sound consistency and regularity effects in word naming. Journal of Memory and Language, 46, 723-750.

Jared, D., \& Kroll, J. F. (2001). Do bilinguals activate phonological representations in one or both of their languages when naming words? Journal of Memory and Language, 44, 2-31.

Jared, D., \& Szucs, C. (2002). Phonological activation in bilinguals: Evidence from intelingual homograph naming. Bilingualism, Language, \& Cognition, 5, 225-239.

Jouravlev, O., \& Lupker, S. J. (2015). Lexical stress assignment as a problem of probabilistic inference. Psychonomic Bulletin \& Review, 2, 1174-1192.

Katz, L., \& Feldman, L. B. (1983). Relation between pronunciation and recognition of printed words in deep and shallow orthographies. Journal of Experimental Psychology: Learning, Memory, and Cognition, 9, 157-166.

Kelly, L., Bard, E., \& Sotillo, C. (1998) Lexical activation by assimilated and reduced tokens. Proceedings of the Fifth International Conference on Spoken Language Processing (ICSLP'98), 1, 875-878.

Levelt, W. J. M., Roelofs, A., \& Meyer, A. S. (1999). Multiple perspectives on lexical access. Reply to commentaries. Behavioral and Brain Sciences, 22, 61-72.

Marslen-Wilson, W. D., \& Welsh, A. (1978). Processing interactions and lexical access during word recognition in continuous speech. Cognitive Psychology, 10, 29-63.

Mattoso Camara Jr., J. (1953). Para o Estudo da Fonêmica Portuguesa. Rio de Janeiro: Organização Simões.

Meara, P., \& Milton, J. (2006). X-Lex: the Swansea Vocabulary Levels Test. In Coombe, C., Davidson, P. and Lloyd D. (Eds.) Proceedings of the 7th and 8th Current Trends in English Language testing (CTELT) Conference, vol 4. UAE; TESOL Arabia, pp 29-39.

Meyer, A. S. (1990). The time course of phonological encoding in language production: The encoding of successive syllables of a word. Journal of Memory and Language, 29, 524-545.

Meyer, A. S. (1991). The time course of phonological encoding in language production: Phonological encoding inside a syllable. Journal of Memory and Language, 30, 6969.

Monsell, S., Doyle, M. C., \& Haggard, P. N. (1989). Effects of frequency on visual word recognition tasks: Where are they? Journal of Experimental Psychology: General, 118, 43-71.

Nobre-Oliveira, D. (2007). The effects of training on the learning of American English vowels by native Brazilian Portuguese speakers. (Doctoral Thesis) Universidade Federal de Santa Catarina. 
Perfetti, C. A., \& Dunlap, S. (2008). Learning to read: General principles and writing system variations. In K. Koda and A. Zehler (Eds.), Learning to read across languages (pp. 13-38). Mahwah, NJ: Erlbaum.

Perry, C., Ziegler, J. C., \& Zorzi, M. (2010). Beyond single syllables: large-scale modeling of reading aloud with the Connectionist Dual Process (CPD++) model. Cognitive Psychology, 61, 106-151.

Post da Silveira, A., van Heuven, V., Caspers, J., \& Schiller, N. O. (2014). Dual activation of word stress from orthography: The effect of the cognate status of words on the production of L2 stress. Dutch Journal of Applied Linguistic, 3, 2, 170-196.

Post da Silveira, A., \& van Leussen, J. W. (2015). Generating a bilingual lexical corpus using interlanguage normalized Levenshtein distances. In: Proceeding of the $18^{\text {th }}$ International Conference of Phonetic Sciences (XVII ICPhS), Glasgow, UK.

Primativo, S., O'Brien, S., Paizi, D., Rinaldi, P., Arduino, L. S., \& Burani, C. (2013). Bilingual vocabulary size and lexical reading in Italian. Acta Psychologica, 3, 554562.

Protopapas, A. (2006ab). On the Use and Usefulness of Stress Diacritics in Reading Greek. Reading and Writing, 19, 171-198.

Protopapas, A., Gerakaki, S., \& Alexandri, S. (2006). Lexical and default stress assignment in reading Greek. Journal of Research in Reading, 29 (4), 418-432.

Rastle, K., \& Coltheart, M. (2000). Lexical and nonlexical print-to-sound translation of disyllabic words and nonwords. Journal of Memory and Language. 42, 3, 342364.

Roelofs, A. (1997). The WEAVER model of word-form encoding in speech production. Cognition, 64, 249-284.

Santos, D. \& Bick, E. (2000). Providing Internet access to Portuguese corpora: the AC/DC project. In M. Gavrilidou, G. Carayannis, S. Markantonatou, S. Piperidis, \& G. Stainhauer (Eds.), Proceedings of the Second International Conference on Language Resources and Evaluation (LREC 2000) (pp. 205-210), Athens, Greece.

Schepens, J., Dijkstra, T., \& Grootjen, F. (2012). Distributions of cognates in Europe as based on Levenshtein distance. Bilingualism: Language and Cognition, 15, 1, 157-166.

Seidenberg, M. S., \& McClelland, J. L. (1989). A Distributed, Developmental Model of Word Recognition and Naming. Psychological Review, 96, 523-568.

Smits, E., Martinsen, H., Dijkstra, T., \& Sandra, D. (2006). Naming interlingual homographs: Variable competition and the role of the decision system. Bilingualism: Language and Cognition, 5, 225-239.

Smits, E., Sandra, D., Martinsen, H. \& Dijkstra, A. (2009). Phonological inconsistency in word naming: Determinants of the interference effect between languages. Bilingualism: Language and Cognition, 12, 23-39.

Sulpizio, S., Burani, C., Colombo, L. (2015). The process of stress assignment in reading aloud: critical issues from studies on Italian. Sci. Stud. Read. 19, 5-20.

Sulpizio. S, \& Colombo, L. (2017). Early markers of lexical stress in visual word recognition. Memory and Cognition, 1-13.

van Heuven, W. J. B., Dijkstra, A., \& Grainger, J. (1998). Orthographic Neighborhood Effects in Bilingual Word Recognition. Journal of Memory and Language, 39, 458483. 
van Leerdam, M. (2005). Dynamics of Phonological Coding in Bilingual Visual Word Perception. (Doctoral Thesis), Universiteit van Amsterdam. Provided by the author.

Weber, A., \& Broersma, M. (2012). Spoken word recognition in second language acquisition. In C.A. Chapelle (Ed.). The Encyclopedia of Applied Linguistics, Bognor Regis: Wiley-Blackwell, 5368-5375.

Yap, M. J., \& Balota, D. A. (2009). Visual word recognition of multisyllabic words. Journal of Memory and Language, 60, 502-529.

Ziegler, J. C., \& Goswami, U. C. (2005). Reading acquisition, developmental dyslexia and skilled reading across languages: A psycholinguistic grain size theory. Psychological Bulletin, 131(1), 3-29.

Recebido em: 25/07/2019

Aceito em: 13/11/2019 